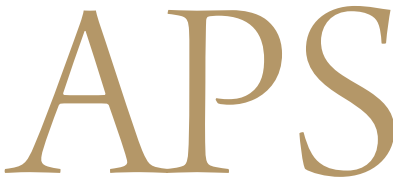

Archives of Plastic Surgery

\title{
One Stage Reconstruction of Skull Exposed by Burn Injury Using a Tissue Expansion Technique
}

\author{
Jae Young Cho, Young Chul Jang, Gi Yeun Hur, Jang Hyu Koh, Dong Kook Seo, \\ Jong Wook Lee, Jai Koo Choi \\ Department of Plastic and Reconstructive Surgery, Hangang Sacred Heart Hospital, Hallym University Medical Center, Seoul, Korea
}

Background An area of the skull exposed by burn injury has been covered by various methods including local flap, skin graft, or free flap surgery. Each method has disadvantages, such as postoperative alopecia or donor site morbidities. Due to the risk of osteomyelitis in the injured skull during the expansion period, tissue expansion was excluded from primary reconstruction. However, successful primary reconstruction was possible in burned skull by tissue expansion.

Methods From January 2000 to 2011, tissue expansion surgery was performed on 10 patients who had sustained electrical burn injuries. In the 3 initial cases, removal of the injured part of the skull and a bone graft was performed. In the latter 7 cases, the injured skull tissue was preserved and covered with a scalp flap directly to obtain natural bone healing and bone remodeling.

Results The mean age of patients was $49.9 \pm 12.2$ years, with 8 male and 2 female. The size of the burn wound was an average of $119.6 \pm 36.7 \mathrm{~cm}^{2}$. The mean expansion duration was $65.5 \pm 5.6$ days, and the inflation volume was an average of $615 \pm 197.6 \mathrm{~mL}$. Mean defect size was $122.2 \pm 34.9 \mathrm{~cm}^{2}$. The complications including infection, hematoma, and the exposure of the expander were observed in 4 cases. Nonetheless, only 1 case required revision.

Conclusions Successful coverage was performed by tissue expansion surgery in burned skull primarily and no secondary reconstruction was needed. Although the risks of osteomyelitis during the expansion period were present, constant coverage of the injured skull and active wound treatment helped successful primary reconstruction of burned skull by tissue expansion.

Keywords Tissue expansion / Burn / Skull
Correspondence: Young Chul Jang Department of Plastic and Reconstructive Surgery, Hangang Sacred Heart Hospital, Hallym University Medical Center, 12 Beodeunaru-ro 7-gil, Yeongdeungpo-gu, Seoul 150-719, Korea

Tel: +82-2-2639-5701

Fax: +82-2-2671-6122

E-mail: ycjang54@paran.com

Received: 7 Nov 2011 • Revised: 7 Feb 2012 • Accepted: 8 Feb 2012

pISSN: 2234-6163 • elSSN: 2234-6171 • http://dx.doi.org/10.5999/aps.2012.39.2.118 • Arch Plast Surg 2012;39:118-123

\section{INTRODUCTION}

Burn wounds require different treatments depending on their location and severity. The scalp is the only area in the body with dense hair patterns and reconstructive options are therefore limited. Scalp wounds with calvarial exposure present a complex clinical challenge and require a systematic approach for reconstruction. Local flaps are ideal for small wounds but are rarely adequate for larger defects. Skin grafts can be a useful option, but require removal of the outer table, thus increasing the complexity and risks of the reconstruction. Skin grafts on trabecular bone also break down easily. A free flap is an option, but requires

Copyright $(92012$ The Korean Society of Plastic and Reconstructive Surgeons

This is an Open Access article distributed under the terms of the Creative Commons Attribution Non-Commercial License (http://creativecommons.org/

licenses/by-nc/3.0/) which permits unrestricted non-commercial use, distribution, and reproduction in any medium, provided the original work is properly cited.

www.e-aps.org 
microvascular expertise and a complex, multi-staged reconstructive effort with the possibility of donor-site morbidity. Scalptissue expansion is a validated, reliable, and safe technique for the treatment of alopecia and has been commonly used in secondary reconstruction in skull injury [1-3]. In the acute stage, the wound is excised and temporarily closed with a skin graft or flap. Tissue expansion is initiated once there is stable coverage. Austad et al. [4] argued against tissue expansion in acute injuries because of the risk of contamination and implant exposure. However, tissue expansion was used successfully in our series for the primary reconstruction of burned skulls, with acceptable complications and good long-term results. This paper reports our 10 years of experience and a review of the literature.

\section{METHODS}

\section{Study subjects}

From January 2000 to 2011, 10 patients presented to the Hangang Sacred Heart Hospital with a burned scalp and an exposed skull after sustaining an electrical burn injury.

\section{Surgical methods}

Rectangular type expanders (Nagosil, Nagor Ltd., Glasgow, UK) were used. The injection port of the expander was replaced with a mini dome valve prior to use. The air within the expander was removed completely, and the four corners of the expander were folded gently to prevent perforation of the flaps by the expander. The horizontal and vertical sides of the space where the expander would be inserted were larger than the entire area by approximately 2 to $3 \mathrm{~cm}$ when compressed without sharply folding the four corners of the tissue expander. These sides were drawn in order to prevent the folding of the tissue expander during its insertion. Upon the insertion of the tissue expander, an incision was made at the boundary of the skull's injured area. The length was approximately half of the compressed tissue expander. Through this incision, a small pouch was made by subgaleal dissection; a silicone tube was placed by preparing a tunnel that penetrated the skin area away from the tissue expander. Hemostasis was performed on bleeding areas by electrocautery. The absence of bleeding was verified by washing with saline; a tissue expander was inserted into the prepared pouch. Prior to the insertion, leakage tests were performed using saline, and the air within the tissue expander was removed. After the insertion, the expander was inflated with 20 to $30 \mathrm{~mL}$ saline up to the volumein which the tissue expander unfolded, a drain was installed, and a two-layer suture was performed. After surgery, a Hemovac (Zimmer Inc., Warsaw, IN, USA) was used to prevent hematoma, and it was maintained from 5 to 7 days after surgery.
Starting 2 weeks after the insertion, 5 to $10 \mathrm{~mL}$ saline was injected all at once, 4 to 5 times a week at our outpatient clinic for approximately 9 to 11 weeks while assessing the development of side effects (e.g., flares in the flap, paleness, necrosis). During the expansion period, constant skull coverage was maintained with foam dressing materials such as Mepilex (Mölnycke Health Care $\mathrm{AB}$, Goteborg, Sweden) and an antibiotic ointment such as Bactroban (GlaxoSmithKline, Middlesex, United Kingdom) or Teramycin (PT Pfizer Inc., New York, NY, USA) to prevent skull desiccation or the development of osteomyelitis. In addition, frequent and active wound treatment was performed by wound dressing and irrigation with normal saline 3 to 4 times a week. Preventive antibiotics were prescribed during the expansion period. When the expansion reached the desired level, the tissue expander was removed. Granulation tissue and necrotic tissue were removed and the injured skull was resected or burred by a diamond burr (Asculap Inc., Tuttlingen, Germany). The affected area was covered with a displacement, advancement, or rotation scalp flap. In the initial period, after the removal of injured skull tissue, costal cartilage or adjacent bone tissue was divided into two and grafted to the skull defect. In 7 cases which were done recently, the injured skull was preserved and covered by a scalp flap directly. By preserving the injured skull and covering it with expanded vascular-rich scalp tissue, the burned skull was successfully primarily reconstructed in all 7 cases.

\section{RESULTS}

The sex of the patients, their age, injured sites, the type and number of tissue expanders used, the duration of the expansion period, expansion volume, surgery outcomes, complications, and the length of the follow-up period are shown in Table 1.

Out of 10 patients, 8 were male. The mean age of the patients was $49.9 \pm 12.2$ years (Table 1 ). The temporal region was the most prevalent with 5 cases, followed by the occipital area in 3 cases, the frontal area in 1 case, and the parietal area in 1 case. The average defect size was $119.6 \pm 36.7 \mathrm{~cm}^{2}$. The number of tissue expanders applied to 10 patients was 13 . The expansion period was between 63 days and 80 days; the average was $65.5 \pm 5.6$ days, depending on the location and size of the lesion. The total volume of saline injected into the tissue expanders was from 345 to $925 \mathrm{~mL}$, and the average was $615 \pm 197.6 \mathrm{~mL}$. An average of $8 \%$ of volume was over-expanded in comparison of expanders. In 7 cases, 1 tissue expander was used for reconstruction. For 3 cases, 2 tissue expanders were used. Complications were observed in 4 cases. Infection, which was caused by osteomyelitis that developed in the injured bone, occurred in 2 cases: hematoma in 1 case and exposure of the expander due to skin 
necrosis during expansion in another case. Among the 4 cases with complications, secondary revision was needed in 1 case in which osteomyelitis was not cured after 3 additional months of treatment and a bone debridement operation was subsequently performed. After revision, the wound was cured and no recurrence was observed in 1 to 10 years of follow-up care (Table 1 ).

Table 1. Case summary

\begin{tabular}{|c|c|c|c|c|c|c|c|c|}
\hline & Sex/Age & Lesion & $\begin{array}{c}\text { Expansion } \\
\text { duration }\end{array}$ & $\begin{array}{l}\text { Wound size } \\
\left(\mathrm{cm}^{2}\right)\end{array}$ & $\begin{array}{c}\text { Type } \\
\text { (mLRTC) }\end{array}$ & $\begin{array}{l}\text { Inflation volume } \\
\qquad(\mathrm{mL})\end{array}$ & Complications & $\begin{array}{l}\text { Follow-up } \\
\text { period (yr) }\end{array}$ \\
\hline 1 & $\mathrm{M} / 50$ & Left temporal & 65 & 110 & 300,400 & 815 & - & 10 \\
\hline 2 & $\mathrm{M} / 47$ & Left temporal & 63 & 150 & 400,500 & 950 & - & 10 \\
\hline 3 & $M / 38$ & Frontal & 69 & 84 & 500 & 515 & - & 10 \\
\hline 4 & $\mathrm{M} / 47$ & Parietal & 60 & 110 & 500 & 520 & Osteomyelitis & 6 \\
\hline 5 & $\mathrm{M} / 49$ & Occipital & 70 & 156 & 500 & 615 & - & 5 \\
\hline 6 & $M / 58$ & Left temporal & 80 & 192 & 400,500 & 925 & Osteomyelitis & 5 \\
\hline 7 & $\mathrm{M} / 76$ & Occipital & 62 & 88 & 300 & 345 & Hematoma & 3 \\
\hline 8 & $\mathrm{~F} / 78$ & Left temporal & 68 & 132 & 500 & 510 & Expander exposure & 1 \\
\hline 9 & $\mathrm{~F} / 57$ & Occipital & 65 & 90 & 400 & 450 & - & 1 \\
\hline 10 & $\mathrm{M} / 49$ & Left temporal & 64 & 110 & 500 & 505 & - & 4 \\
\hline
\end{tabular}

\section{Fig. 1. Tissue expansion with bone graft}

(A) Full expanded state of two expanders. (B) Harvested and bihalved rib bone. (C) Debridement including dead cortical bone. (D) Rib graft to skull defect. (E) Immediately after expander removal and local flap operation. (F) 3D CT image postoperative 1 year. The grafted bone is visibly viable. $(\mathrm{G})$ After 10 years of follow-up. Good hair volume and direction.
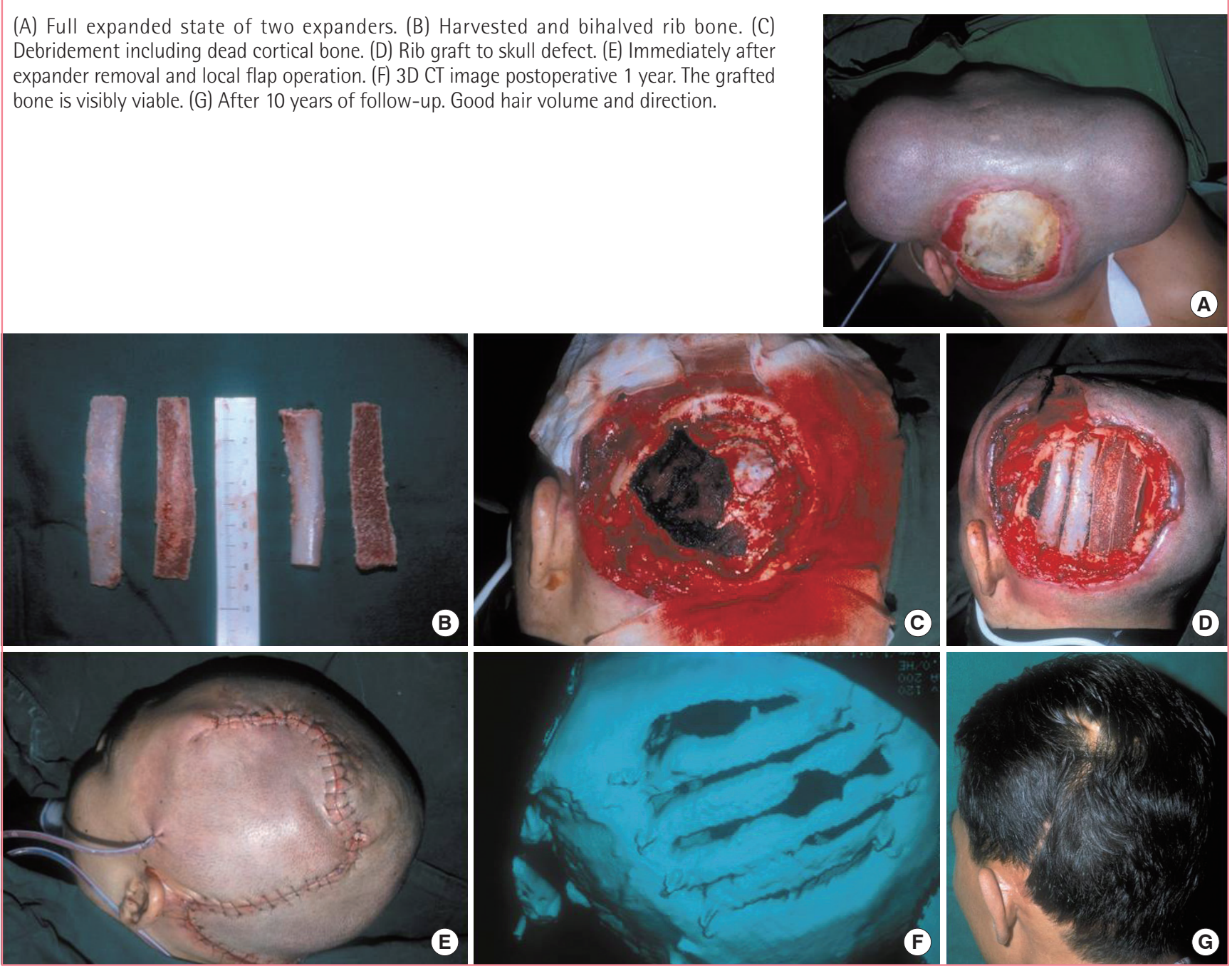


\section{CASES}

\section{Case 1}

A 47-year-old male patient was admitted due to a scalp injury $(10 \times 15 \mathrm{~cm})$ caused by an electric burn. Two tissue expanders $(400 \mathrm{~mL}$ and $500 \mathrm{~mL}$ ) were inserted. For 63 days, saline (up to $950 \mathrm{~mL}$ ) was injected, while necrotic soft tissue and necrotic bone tissue were removed. A bone graft was performed by using a bihalved rib, followed by covering the area with an expanded flap by advancing and rotating. In the 3D CT performed 1 year after surgery, well-engrafted bones were detected. In the followup observation 10 years after surgery, satisfactory results were observed in the volume and direction of hair growth (Fig. 1).

\section{Case 2}

A 49-year-old male patient sustained a scalp injury $(13 \times 12$ $\mathrm{cm})$ caused by an electric burn. An incision was made along the parietal area of the scalp injury where 1 tissue expander (500 $\mathrm{mL}$ ) was inserted. After surgery, $615 \mathrm{~mL}$ of saline was injected for 70 days. After the removal of necrotic tissues, injured bone was covered by advancing a scalp flap. One year after surgery the scalp showed natural bone healing and remodeling. After surgery, osteomyelitis was not observed during a 5-year followup period (Fig. 2).

\section{DISCUSSION}

Numerous methods have been introduced for the reconstruction of the burned skull. For small lesions $(<3 \mathrm{~cm})$, primary closure can be effected $[5,6]$. Split-thickness skin grafts can be combined with a staged procedure, such as tissue expansion, to provide temporary wound coverage. The primary advantage of split-thickness skin grafting for scalp reconstruction is its technical simplicity. The disadvantage is the cosmetically inferior appearance of the skin graft compared with a scalp reconstructed with hair-bearing tissue. In addition, the long-term stability of coverage tends to be a problem. Local tissue arrangement including transposition, advancement, and rotation flaps have been employed in scalp reconstruction. Orticochea [7] published his four-flap scalp reconstructive technique by which

\section{Fig. 2. Tissue expansion without bone graft}

(A) Before operation, $13 \times 12 \mathrm{~cm}$ skull defect. (B) After one tissue expander insertion. (C) After full expansion. (D) Immediately after expander removal and local flap. (E) Bone scan postoperative 1 year. No evidence of osteomyelitis. (F) After 5 years follow-up. Good hair volume and direction.
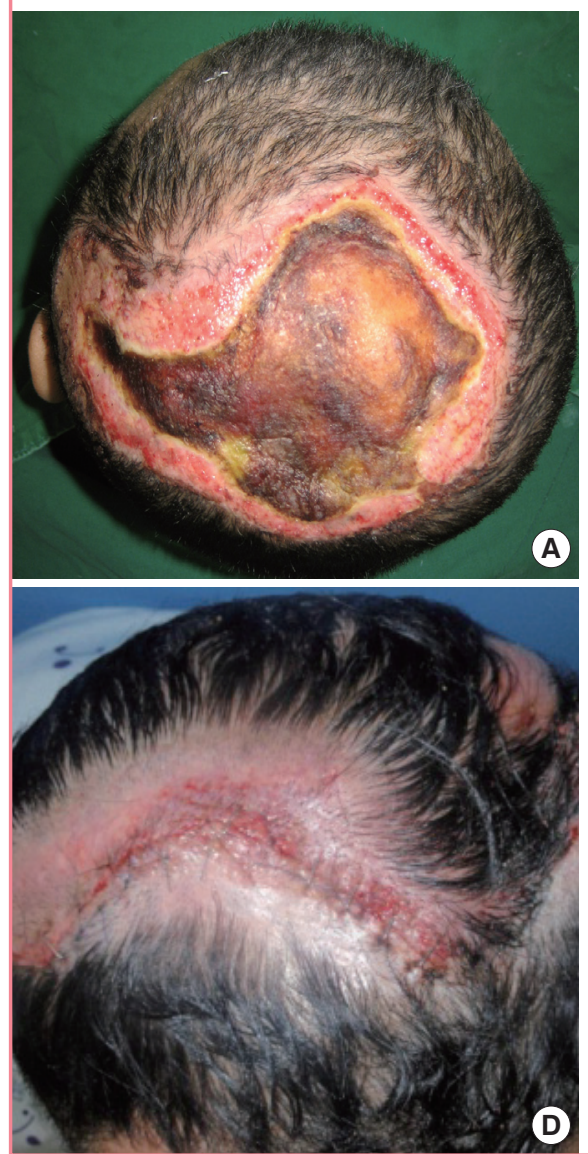
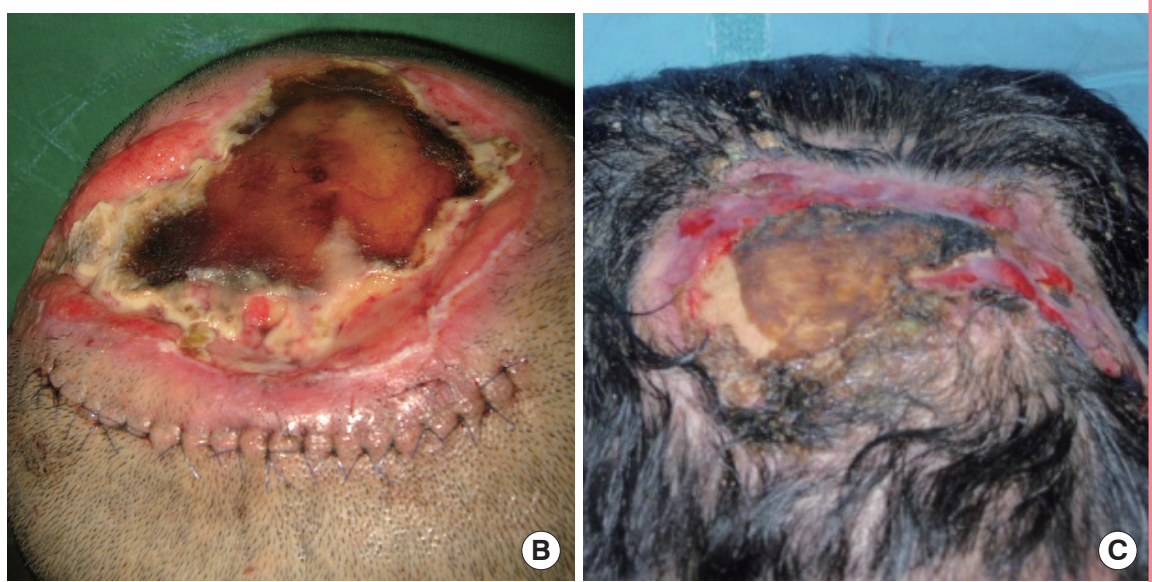

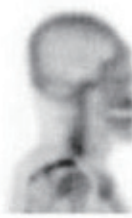

RT-LAT

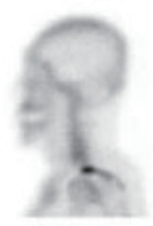

LT-LAT

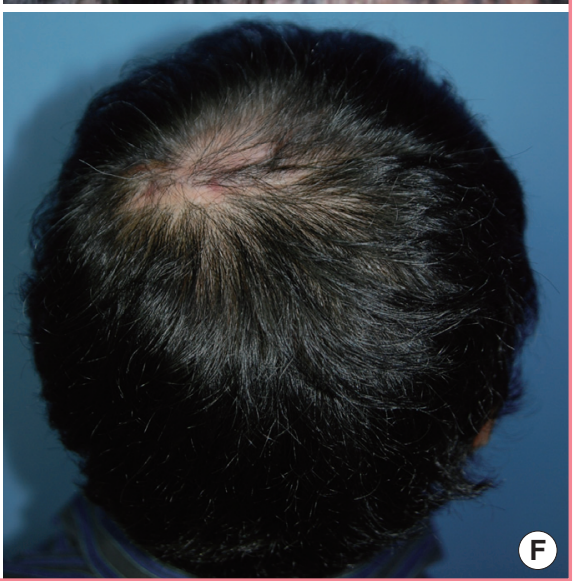


defects as large as $30 \%$ of the cranium can be closed. The advantages of scalp flaps include excellent cosmesis, replacement of hair-bearing defects with hair-bearing scalp, a single donor site, and the technical simplicity of the procedure. Potential drawbacks include the relative lack of scalp mobility and the potential to displace mobile structures, such as the eyebrow or hairline. Tissue expansion is particularly useful in scalp reconstruction because it provides the surgeon with the opportunity to replace missing tissue with a tissue of similar quality and thickness [810]. The technique increases the amount of locally available tissue, preserves sensation, and maintains hair follicles and adnexal structures. In addition, tissue expansion produces a delay phenomenon, increasing the vascularity of the expanded flap [4]. Defects up to $50 \%$ of the scalp can be reconstructed without a noticeable change in hair density. Many authors felt afraid to place a tissue expander next to an open wound because it could predispose it to infection and may pull on the wound margins, thus enlarging the wound and risking prosthetic exposure $[11,12]$. The unique anatomy of the scalp, however, allows for safe and expeditious expansion despite these risks. The blood supply of the scalp is robust, hence decreasing the chances of infection. The tissue expanders placed under the scalp expand only the tissues directly above them. Perhaps because of the unyielding galea aponeurotica, the scalp about 1 to $2 \mathrm{~cm}$ away from the expander margin is generally undisturbed by tissue expansion. As a result, proximate placement of multiple tissue expanders can be well tolerated despite open wounds. This allows for the use of expansion, which is the most favorable reconstructive technique for the scalp, as it provides durable hairbearing tissue [13]. However, one of the major disadvantages of tissue expansion is the length of time it takes to expand the adjacent scalp. Expansion periods often take 2 to 3 month and the risk of osteomyelitis of the exposed skull is increased during that period. For its prevention, the exposed skull was constantly covered with foam dressing materials and antibiotic ointment to maintain a moist environment. Wounds were treated and irrigated every other day. Appropriate antibiotics were intravenously administered during the expansion period. By these efforts, preservation of the damaged skull and coverage with expanded scalp tissue was successful. Oishi and Luce [14] have also recommended preservation of the bone and coverage with well-vascularized tissue when the skull is not grossly necrotic. Osteomyelitis was shown in 2 of the 10 cases. One patient was completely cured by wound dressing and continuous injection of antibiotics within approximately 3 months. Another patient was completely cured by revision of bone curettage. Afterwards, the osteomyelitis was completely cured and no recurrence was observed in 2 to 5 years of follow-up care. For the treatment of the injured skull in the initial period, bone grafting was performed immediately after the removal of the injured parts. In the latter period, the bone frame was maintained by preserving the injured bones. Natural healing and bone remodeling were induced by covering the injury with a flap with sufficient blood flow. The procedure was successful. With regard to the histological findings observed after the expansion of the skin by applying tissue expanders, the thickness of the epidermis was maintained [15-18]. On the other hand, the thickness of the dermis was decreased. Collagen synthesis was increased in the dermal layer, which also showed myofibroblasts. Adipocytes became thin and the thickness of the muscles was reduced. The size and number of dermal blood vessels were increased in the order of the capillaries, veins, and arteries, from least to most extensive increase. Thus, the blood supply in the expanded skin was increased relative to pre-expansion. It was concluded that flaps with such increased blood supply play an important role in bone remodeling and in the prevention and treatment of osteomyelitis. In addition, to minimize the development and progression of osteomyelitis, rapid tissue expansion was induced. The entire tissue expansion procedure was completed in between 63 days and 80 days. Rapid tissue expansion was performed by injecting 5 to $10 \mathrm{~mL}$ of saline at a time, 4 to 5 times a week. At each expansion procedure, flares in the stretched scalp tissues and changes in skin thickness were examined carefully. Thus, exposure of the tissue expander during the expansion did not occur except in 1 case, in which the patient developed skin necrosis. Even in this case, the exposure of the expander occurred after the substantial progression of the tissue expansion procedure; hence, normal tissue expansion could be completed.

Most third or fourth degree burns that could induce skull injury are primarily electric burns caused by a current higher than 22,000 volts. Even in an electric burn injury, the extremities such as the hand and foot are the areas most commonly injured; cases with skull injury are rare. Hence, during the 10-year follow-up observation period, only 10 cases could be examined. Thus, it is necessary to obtain more clinical research results by securing more cases.

Reconstruction was successfully performed on 10 patients with burned skulls by using a tissue expander in the acute stage. Even in cases of an exposed skull and when the occurrence of osteomyelitis was suspected, by combining aggressive treatment and the prevention of osteomyelitis with tissue expansion surgery, the burned skull could be reconstructed successfully. During that time, efforts should be made to rapidly expand tissue and treat the wound. Through such efforts, the burned skull could be successfully reconstructed by a one-stage tissue expansion surgery with acceptable complications and a good long- 
term outcome.

\section{REFERENCES}

1. MacLennan SE, Corcoran JF, Neale HW. Tissue expansion in head and neck burn reconstruction. Clin Plast Surg 2000;27:121-32.

2. Manders EK, Graham WP 3rd, Schenden MJ, et al. Skin expansion to eliminate large scalp defects. Ann Plast Surg 1984;12:305-12.

3. Neale HW, High RM, Billmire DA, et al. Complications of controlled tissue expansion in the pediatric burn patient. Plast Reconstr Surg 1988;82:840-8.

4. Austad ED, Pasyk KA, McClatchey KD, et al. Histomorphologic evaluation of guinea pig skin and soft tissue after controlled tissue expansion. Plast Reconstr Surg 1982;70:704 10.

5. Cox AJ 3rd, Wang TD, Cook TA. Closure of a scalp defect. Arch Facial Plast Surg 1999;1:212-5.

6. Ritchie AJ, Rocke LG. Staples versus sutures in the closure of scalp wounds: a prospective, double-blind, randomized trial. Injury 1989;20:217-8.

7. Orticochea M. Four flap scalp reconstruction technique. $\mathrm{Br}$ J Plast Surg 1967;20:159-71.

8. Zuker RM. The use of tissue expansion in pediatric scalp burn reconstruction. J Burn Care Rehabil 1987;8:103-6.

9. Antonyshyn O, Gruss JS, Zuker R, et al. Tissue expan- sion in head and neck reconstruction. Plast Reconstr Surg 1988;82:58-68.

10. Wieslander JB. Repeated tissue expansion in reconstruction of a huge combined scalp-forehead avulsion injury. Ann Plast Surg 1988;20:381-5.

11. Kiyono M, Matsuo K, Fujiwara T, et al. Repair of scalp defects using a tissue expander and Marlex mesh. Plast Reconstr Surg 1992;89:349-52.

12. Matthews RN, Missotten FE. Early tissue expansion to close a traumatic defect of scalp and pericranium. Br J Plast Surg 1986;39:417-21.

13. Ridgway E, Taghinia A, Donelan M. Scalp-tissue expansion for a chronic burn wound with exposed calvarium. J Plast Reconstr Aesthet Surg 2009;62:e629-30.

14. Oishi SN, Luce EA. The difficult scalp and skull wound. Clin Plast Surg 1995;22:51-9.

15. Pasyk KA, Austad ED, McClatchey KD, et al. Electron microscopic evaluation of guinea pig skin and soft tissues "expanded" with a self-inflating silicone implant. Plast Reconstr Surg 1982;70:37-45.

16. Pasyk KA, Argenta LC, Austad ED. Histopathology of human expanded tissue. Clin Plast Surg 1987;14:435-45.

17. Sasaki GH, Pang CY. Pathophysiology of skin flaps raised on expanded pig skin. Plast Reconstr Surg 1984;74:59-67.

18. Cherry GW, Austad E, Pasyk K, et al. Increased survival and vascularity of random-pattern skin flaps elevated in controlled, expanded skin. Plast Reconstr Surg 1983;72:680-7. 


\section{Discussion}

\section{Discussion: One Stage Reconstruction of Skull Exposed by Burn Injury Using Tissue Expansion Technique}

Sung-No Jung, Soo-Hyung Han

Department of Plastic and Reconstructive Surgery, Uijeongbu St. Mary's Hospital, The Catholic University of Korea School of Medicine, Seoul, Korea

Many surgical procedures claim to show high success rates in scalp reconstruction. However, there has been a limited case of injury to the scalp, specifically due to electrical burn which is severe as to exhibit skull exposure. Moreover, there is scarce number of papers discussing treatment of this certain kind of trauma with tissue expansion technique. We think this article is of enough value to report 10 successful cases of scalp reconstruction using tissue expanders over a long period as 12 years.

But we think there are some shortcomings in this article. The authors seem to overly emphasize their successful outcome without the need of additional surgery by describing the procedure as "one stage" in the title of their study. However, tissue expansion requires a minimum of 2 operative stages; placing and removing the expander. It could even be considered as a 3 step procedure if the expansion period is also taken into account. The term "one stage" in this article is contradictory to the essential nature of expansion technique.

Also, despite the fact that there are many new articles addressing scalp reconstruction, authors have included many outdated citations. Most of the citations are published in 1980s, except only one reference that was published in 2009. We hereupon want to supplement the readers with ideas that have recently come up in numerous journals.

Classic concept of reconstructive ladder can also be applied to scalp reconstruction, thereby allowing whole spectrum of reconstruction methods like healing with secondary intention, direct closure, skin graft, local and distant flap [1]. Lesion as small as $3 \mathrm{~cm}$ can be closed directly and lesions larger than $3 \mathrm{~cm}$ in size and/or complex in quality can be covered with skin graft, local flap and distant flap. Healing with secondary intention is advantageous by the fact that it does not rely on any certain vascular pedicle, does not require secondary surgery, and is convenient in detecting and managing tumor recurrence. But prolonged moist environment has to be maintained to achieve healing. Direct closure is cosmetically elegant, technically simple, quickly healed, and easily manageable in terms of wound care but cannot be employed in large defects. There are some attempts to overcome this drawback using double purse-string suture [2]. Skin graft allows coverage of large sized defect in presence of healthy vascular bed, but still has problems regarding poor cosmetic outcome and donor site morbidity. Local flaps - advancement flap, rotation flap, transposition flap - are very useful in covering large defects by preserving a certain vascular pedicle [3]. Wound management is simple, healing is fast, and cosmetically satisfying. However, complications like infection, hematoma, and wound dehiscence can arise in result of giving additional tissue manipulations such as additional incision or tissue undermining. Furthermore, a defect that has some possibility of residual tumor in the wound bed is not a good candidate for local flap coverage. In case of nearly total defect in the scalp, distant flaps as various as anterolateral thigh flap, latissimus dorsi muscle flap, radial forearm free flap, transverse rectus abdominus myocutaneous flap can be used [4-6]

Alloplastic material has recently become available in scalp reconstruction. There are a few case reports covering full-thickness scalp defect through one or two-stage procedure using artificial dermis, dermal regeneration template, and bovine collagen construct [7-11].

Tissue expansion is a good technique that complies to the principles of scalp reconstruction, simply described as "replace like tissue with like tissue" by Eeedy et al. [1]. It is a useful method that can be considered as an option regardless of what level of reconstructive ladder the defect lies in. In case of skull exposure as mentioned in this article, galeal flap, multiple burring or chiseling can be done to make a healthy vascular bed and covering it with a skin graft is possible, but it brings a poor cosmetic outcome compared to tissue expansion $[12,13]$. But tissue expansion requires 2 to 3 months of expansion period, and decreased hair density becomes a problem when trying to cover a defect over $50 \%$ of total scalp surface area [14].

Developments in scalp reconstruction include the use of vacuumassisted closure (VAC). We now have enough theoretical basis how VAC systems improve local blood flow, increase granulation tissue formation, minimize bacterial colonization [15]. Many successful treatments have also been reported using this method [16]. In the article of our interest, open wound was managed with frequent dressing and irrigation, but our experience suggests the wound be treated with VAC. We would posit that VAC system will reduce the risk of wound problem.

\section{REFERENCES}

1. Leedy JE, Janis JE, Rohrich RJ. Reconstruction of acquired scalp defects: an algorithmic approach. Plast Reconstr Surg 2005; $116: 54 \mathrm{e}-72 \mathrm{e}$.

2. Cruz AP, Campbell RM, Perlis CS, et al. Double purse-string

Copyright $(\odot 2012$ The Korean Society of Plastic and Reconstructive Surgeons

This is an Open Access article distributed under the terms of the Creative Commons Attribution Non-Commercial License (http://creativecommons.org/

licenses/by-nc/3.0/) which permits unrestricted non-commercial use, distribution, and reproduction in any medium, provided the original work is properly cited. 
closure for scalp and extremity wounds. Dermatol Surg 2007;33:369-73.

3. Rohit S, Sirohi D, Sengupta P, et al. Superficial temporal fascia pedicled v-y advancement flap for scalp reconstruction. J Maxillofac Oral Surg 2010;9:410-4.

4. Wang HT, Erdmann D, Olbrich KC, et al. Free flap reconstruction of the scalp and calvaria of major neurosurgical resections in cancer patients: lessons learned closing large, difficult wounds of the dura and skull. Plast Reconstr Surg 2007;119:865-72.

5. Hallock GG. Long-term superiority of composite versus muscle-only free flaps for skull coverage. Ann Plast Surg 2004;52:507-10.

6. Ozkan O, Coskunfirat OK, Ozgentas HE, et al. Rationale for reconstruction of large scalp defects using the anterolateral thigh flap: structural and aesthetic outcomes. J Reconstr Microsurg 2005;21:539-45.

7. Komorowska-Timek E, Gabriel A, Bennett DC, et al. Artificial dermis as an alternative for coverage of complex scalp defects following excision of malignant tumors. Plast Reconstr Surg 2005;115:1010-7.

8. Koenen W, Goerdt S, Faulhaber J. Removal of the outer table of the skull for reconstruction of full-thickness scalp defects with a dermal regeneration template. Dermatol Surg 2008;34:357-63.

9. Kinsella CR Jr, Grunwaldt LJ, Cooper GM, et al. Scalp reconstruction: regeneration with acellular dermal matrix. J Craniofac Surg 2010;21:605-7.

10. Wilensky JS, Rosenthal AH, Bradford CR, et al. The use of a bovine collagen construct for reconstruction of full-thickness scalp defects in the elderly patient with cutaneous malignancy. Ann Plast Surg 2005;54:297-301.

11. Jung SN, Chung JW, Yim YM, et al. One-stage skin grafting of the exposed skull with acellular human dermis (AlloDerm). J Craniofac Surg 2008;19:1660-2.

12. Halpern M, Adams C, Ratner D. Galeal hinge flaps: a useful technique for immediate repair of scalp defects extending to periosteum. Dermatol Surg 2009;35:127-30.

13. Feierabend TC, Bindra RN. Injuries causing major loss of scalp. Plast Reconstr Surg 1985;76:189-94.

14. Antonyshyn O, Gruss JS, Zuker R, et al. Tissue expansion in head and neck reconstruction. Plast Reconstr Surg 1988; 82:58-68.

15. Morykwas MJ, Argenta LC, Shelton-Brown EI, et al. Vacuum-assisted closure: a new method for wound control and treatment: animal studies and basic foundation. Ann Plast Surg 1997;38:553-62.

16. Marathe US, SniezekJC. Use of the vacuum-assisted closure device in enhancing closure of a massive skull defect. Laryngoscope 2004;114:961-4.

Correspondence: Sung-No Jung

Department of Plastic and Reconstructive Surgery, Uijeongbu St. Mary's Hospital, The Catholic University of Korea School of Medicine, 271 Cheonbo-ro, Uijeongbu 480-717, Korea Tel: +82-31-820-3576, Fax: +82-31-847-0301, E-mail: jsn7190@ @atholic.ac.kr

No potential conflict of interest relevant to this article was reported.

Received: 3 Mar 2012 • Revised: 4 Mar 2012 • Accepted: 4 Mar 2012 pISSN: 2234-6163 • elSSN: 2234-6171

http://dx.doi.org/10.5999/aps.2012.39.2.124 • Arch Plast Surg 2012;39:124-125 